\title{
The Effect of Social Capital on the Use of General Practitioners: A Comparison of Immigrants and Non-Immigrants in Ontario
}

\section{L'effet du capital social sur l'utilisation des services d'omnipraticiens : comparaison entre immigrants et non-immigrants en Ontario}

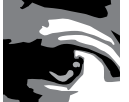 \\ DEBORAH A. SAMEK, MSC \\ Graduate Student, Institute of Health Policy, Management and Evaluation \\ University of Toronto \\ Toronto, $\mathrm{ON}$ \\ AUDREY LAPORTE, PHD \\ Associate Professor, Institute of Health Policy, Management and Evaluation \\ University of Toronto \\ Toronto, ON \\ ERIC NAUENBERG, PHD \\ Associate Professor, Institute of Health Policy, Management and Evaluation \\ University of Toronto \\ Toronto, ON \\ LEILEI SHEN, MA \\ Assistant Professor, Department of Economics \\ Kansas State University \\ Manbattan, KS \\ PETER C. COYTE, PHD \\ Professor, Institute of Health Policy, Management and Evaluation \\ University of Toronto \\ Toronto, ON
}




\begin{abstract}
Social capital, a resource arising from the social interaction among individuals, may be a determinant of medical care use. This study explored the interaction between community- and individual-level social capital and immigrant status on the propensity and frequency of physician visits. The results showed that community social capital, as measured by the Petris Social Capital Index, was not significant in any of the analyses. However, a sense of belonging to the local community tended to decrease the number of doctor visits made by immigrants, while tangible social support increased and affection decreased the frequency of GP consultations by nonimmigrants. Further research is required to determine which types of social capital affect utilization of different health services. These findings also highlight the importance of being aware of potential interactions between the formal and informal components of the healthcare system.
\end{abstract}

\title{
Résumé
}

Le capital social, une ressource qui découle de l'interaction sociale entre les individus, peut être un déterminant de l'utilisation des soins médicaux. Cette étude explore l'influence du capital social communautaire et individuel et du statut d'immigrant sur la propension à utiliser les services du médecin et sur la fréquence des consultations. Les résultats montrent que le capital social communautaire, mesuré à l'aide de l'indice PSCI (Petris Social Capital Index), n'a aucune incidence significative, et ce, pour toutes les analyses. Toutefois, le sens d'appartenance à une communauté locale tend à faire diminuer le nombre de visites au médecin par les immigrants, tandis qu'un soutien social concret fait croître le nombre de consultations des non-immigrants auprès d'un omnipraticien, alors que l'affection la fait décroître. Il faut effectuer d'autres recherches pour déterminer quels types de capital social influent sur l'utilisation des différents services de santé. Ces résultats montrent également l'importance de se renseigner sur les interactions potentielles entre les composantes officielles et non officielles du système de santé.

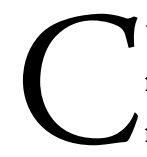

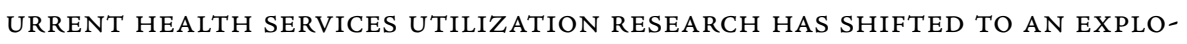
ration of social determinants of health, such as social capital. Social capital is a resource found in the relations among individuals and within the community that can generate positive externalities (Folland 2008; Glaeser et al. 2002). Individual social capital (ISC) can be defined as the level of trust, networking or cooperation that an individual has with society, whereas community social capital (CSC) is the density of trust, networks or cooperation within a given society (Brown et al. 2006; emphasis in the original). Sources of social capital include social networks and religious and community organizations (Brown et al. 2006; Miltiades and Wu 2007; Putnam 2000). Social capital is theorized to affect health services utilization by providing information about the healthcare system, enabling access to the healthcare system and substituting for formal healthcare (Aroian et al. 2001; Deri 2004; Devillanova 2008; Laporte et al. 2008; Mellor and Milyo 2005; Miltiades and Wu 2007; Viladrich 2005). 
Social capital may have a differential effect on immigrants' utilization of healthcare services when compared with native-born individuals. The provision of information about the healthcare system has been identified by researchers as perhaps the most important function of social capital in enabling access to and utilization of healthcare services for immigrants (Aroian et al. 2001; Bhattacharya 2005; Devillanova 2008; Kao 2004; Mellor and Milyo 2005; Viladrich 2005). Leclere and colleagues (1994) found that the family, as perhaps the primary source of social capital for immigrants, plays an important role in how and when individuals seek formal healthcare by facilitating access and serving as a substitute for formal care. Neighbours and friends who are part of the same ethno-cultural group are also instrumental in influencing health services utilization decisions. Deri (2005) has suggested that if formal healthcare is not part of the norms of one's social network, more social capital may lead to decreased utilization of formal healthcare; this may be particularly true for immigrants who have strong beliefs in the superiority of traditional medicine (Ma 1999). Leduc and Proulx (2004) have stated that a high concentration of immigrants in the neighbourhood offers many opportunities to communicate with other immigrants (either of the same or different ethnicity) who are familiar with the healthcare system and who influence the new arrival's initial utilization of services. Moreover, having a high concentration of doctors in the local community who speak the same language increases the probability of utilization for immigrants who prefer to have a doctor from the same ethnic group (Deri 2005; Leduc and Proulx 2004).

Researchers disagree on how immigrants develop their stock of social capital in the new society. Some studies claim that immigrants arrive with social networks already in place in the new community; for example, one of the most important reasons to immigrate to Canada may have been to maintain ties with family and friends who had arrived earlier (Kunz 2005). Wu and Hart (2002) found that immigrants may immigrate with their families, thus maintaining their former network, or also actively create new networks within their ethnic community, the host society or both. Conversely, other researchers have reported that immigrants have few friends and family in the new society and may experience loneliness and depression (Aroian et al. 2001; Ma 1999; McMichael and Manderson 2004). Regardless of how immigrants recreate new social networks, the family is the most important source of social capital for immigrants (Leclere et al. 1994). Moreover, social capital may be more important for immigrants than non-immigrants. A comparison of the impact of social capital between immigrant and nonimmigrant youth has found that immigrant youth have less social capital, but that they reap greater rewards from the little they have compared to native-born youths (Taggart et al. 2003, as cited in Kao 2004). Social capital may be particularly important for immigrants because they may face difficulty accessing formal channels for medical care and other social services.

Immigrant health services utilization is under-researched in Canada; there is evidence, however, that their utilization of health services tends to be suboptimal (Hyman 2001). There is also little information on the impact of social capital on immigrants' utilization of healthcare. An understanding of how social capital influences primary care utilization decisions of immigrants is essential when developing policies and programs to ensure that the 
different immigrant communities receive the healthcare they need. In addition to improving access to healthcare among immigrants, understanding the factors that affect immigrant utilization of healthcare services helps policy makers assess the impact of immigration on the healthcare system and to monitor the accessibility of the system (Laroche 2000; Pavlic et al. 2007). Moreover, immigrants represent valuable "economic, social and demographic assets to their host country" and as such, it is important to ensure they maintain their health over time (Asanin and Wilson 2008: 1271).

Using a similar data set, ${ }^{1}$ this paper explores Laporte and colleagues' (2008) finding that despite controlling for differential access and health status, immigrants were less likely to visit a general practitioner (GP). The purpose of this analysis was to determine how CSC and ISC affect health services utilization for immigrants compared to non-immigrants, controlling for differences in social capital measured both at the individual and the community level. It is hypothesized that CSC will be associated with a decrease in the propensity and intensity of GP consultations for immigrants and non-immigrants, although the magnitude of the effect will be greater for non-immigrants. Canadian-born individuals may find it easier than immigrants to access the community resources that are part of the CSC supply. Given the extensive literature showing the importance of ISC for immigrants and the association between ISC and health services utilization, it is hypothesized that ISC will increase the propensity and intensity of physician consultations for immigrants. It is further hypothesized that the complementary and substitution effects noted by Laporte and colleagues (2008) will be seen in the non-immigrant subsample.

\section{Methods}

\section{Data sources}

Input variables, such as the ISC variables, were selected from Cycle 1.2 of the 2002 Canadian Community Health Survey (CCHS). The CCHS is a cross-sectional survey that contains information related to health status, healthcare use and health determinants of the Canadian population. Cycle 1.2 of the CCHS targeted all Canadians aged 15 years and over living in the 10 provinces. Full-time members of the armed forces, individuals residing in institutions, residents in some remote areas, the homeless and residents of Crown lands or Indian reserves were excluded.

Primary care GP visits were obtained from the Ontario respondents to the CCHS by using their encrypted health card number to link their responses to their 2006-2007 physician claims from the Ontario Health Insurance Program (OHIP). Out of 12,376 individuals, 10,985 people voluntarily agreed to share their information, yielding an agreement rate of $88.8 \%$ (Statistics Canada 2004). After removing respondents with missing values, the final sample was composed of 7,711 individuals, of which 6,042 had at least one primary care physician visit in fiscal year 2006. Individuals were identified using a unique anonymous identifier to maintain confidentiality. A physician visit associated with at least one of 57 fee service codes used to define the basket of services provided by primary care physicians in Ontario was defined as a primary care GP visit. (This information is available upon request.) GP service use is a good measure of healthcare use and access because these visits are initiated by the patient, whereas 
hospitalizations and specialist visits are more likely to be driven by other physicians (Dunlop et al. 2000; Nabalamba and Millar 2007). Furthermore, in Ontario, GP services are publicly funded and provided free at point-of-service to all citizens, including landed immigrants. Thus, there are no financial barriers to accessing care, unlike most other jurisdictions that have user fees.

\section{Social capital measures}

The 2002 CCHS was selected because it contains four ISC variables that have been used in the literature: community belonging, religious attendance, tangible social support and affection. Sense of belonging is operationalized in the CCHS by how the respondent describes his or her sense of belonging to the local community, with a range of answers varying from very strong to very weak (Statistics Canada 2004). Religious attendance is defined in the CCHS by how often a person participates in religious activities or attends religious services or meetings, with the following possible responses: (1) once a week or more, (2) once a month, (3) 3 or 4 times a year, (4) once a year or (5) not at all (Statistics Canada 2004: 240). Religious attendance was coded as equal to 1 if respondents attended at least one service in the previous year. Tangible social support is defined as the provision of material aid or behavioural assistance. Questions about affection ask whether or not the respondent receives or provides any affection (Statistics Canada n.d.). These two latter variables were coded as equal to 1 if the respondent experienced tangible social support or affection, respectively.

The measure of CSC employed in this analysis is the Petris Social Capital Index (PSCI). The PSCI measures the supply of resources that facilitate the development and maintenance of CSC, such as the percentage of population employed in community service organizations (Scheffler and Brown 2008). This measure of CSC is the ratio of paid workers older than 15 to the total number of paid workers ${ }^{2}$ employed according to the following North American Industrial Classification System (NAICS) codes listed in the long form of the 2001 Canadian Census:

\section{1: Religious organizations}

8132: Grant-making and giving organizations

8133: Social advocacy organizations

8134: Civic and social organizations

8139: Business, professional, labour and other membership organizations ${ }^{2}$

The number of paid workers was calculated by summing the number of full-time paid workers (30 hours or more per week) + one-half the number of part-time paid workers (less than 30 hours per week). The PSCI was constructed from the long form of the 2001 Canadian Census, which contains data on the number of paid employees aged 15 years and over in various organizations. The 2001 Census was linked to the $2002 \mathrm{CCHS}$ according to Census Metropolitan Area (CMA, a large urban centre with a population greater than 100,000) and Census Agglomeration area (CA, an urban region with a population of 10,000 
to 100,000) (Statistics Canada 2004). These were the two geographic variables in common between the two data sets. Rural areas were excluded from the analyses because the Census and health administrative data could not be linked for such areas.

Alternatives to the PSCI, such as income inequality, aggregate measures of trust in the community and civic participation, and the Putnam Index, exist in the literature (Ahern and Hendryx 2005; Bryant and Norris 2002; Devillanova 2008; Hendryx et al. 2002; Macinko and Starfield 2001; Subramanian and Kawachi 2004). These indicators were rejected in favour of the PSCI for the following reasons. Income inequality is limited in utility because results from studies conducted outside the United States and for regions smaller than state level are rarely significant (Subramanian and Kawachi 2004). Average measures of individual trust in the community and civic participation tend to decrease in significance after adjustment for individual factors (Subramanian and Kawachi 2004), and these measures were not available for Ontario. Macinko and Starfield (2001) have argued that the Putnam Index may capture the openness or oppressiveness of the government instead of community engagement. The PSCI is attractive because it is not an aggregate of individual measures of social capital and it has been used successfully in the Canadian context (Brown et al. 2006; Laporte et al. 2008). Socio-demographic and health variables include participation in social physical activity (e.g., team sports) in the past three months; age; sex; continent of origin (for immigrants only) (South America, Asia, Africa, Europe - reference group: North America); number of years since immigration to Canada (YSM) ${ }^{3}$; married or common-law; living alone; education (obtained a college degree or higher); household income; full-time employment; drink at least one alcoholic beverage daily; very good, good or poor self-assessed health status (reference group: very poor); reported at least one chronic condition as listed in the CCHS; residence in a Census Agglomeration area.

\section{Statistical analysis}

Economists tend to think about the use of medical care along two dimensions. The first dimension corresponds to the patient's decision to initiate contact with the healthcare system, which determines an individual's propensity to utilize GP services; the second corresponds to the number of visits or intensity of GP services use, in which the physician may play a significant role. Several empirical analyses are consistent with this approach, and various modelling strategies have been proposed to study the idea that the propensity and intensity of healthcare service utilization are determined by two different stochastic processes (e.g., Gerdtham 1997; Pohlmeier and Ulrich 1995). In order to generate hypotheses about how the utilization (i.e., propensity and intensity) of GP services by immigrants and non-immigrants is affected by community and individual social capital, this analysis uses stock of social capital as an input into the demand for medical care both in terms of propensity and intensity of use.

Concern has been raised in the literature that consulting a doctor may result in respondents reporting higher levels of ISC (Laporte et al. 2008), which could result in biased estimates of the observed effects of ISC on utilization. Employing a lagged model (i.e., using future GP visits as a function of past levels of ISC), however, as in this paper, addresses this 
issue. This approach breaks the intra-temporal link between current social capital and current GP use and also accounts for the possibility that it may take time for social capital to have an impact on utilization. A study by Laporte and colleagues (2008), which used current GP visits as the outcome measure, found evidence for a strong role for both the PSCI and community belonging in affecting the health services utilization of Canadians (without differentiating between immigrants and the native-born).

Two statistical approaches were compared because the lagged model may be sensitive to regression technique. In the two-part model with the Heckman correction, the propensity of immigrants to visit a doctor was first estimated with a probit equation. In the second stage, the frequency of physician visits (conditional on having had at least one visit) was estimated by ordinary least squares. The Heckman correction (Heckman 1976; Puhani 2000) is employed to control for the possibility of a selection effect (i.e., the existence of unobservable factors that influence the likelihood that an individual will have a GP visit). Failure to account for this possibility could yield biased estimated coefficients in the intensity equation. A onestage negative binomial (NEGBIN) regression (Greene 2003), which is appropriate when the outcome variable is count data, was also employed because it is less restrictive than other count models, can account for over-dispersion, and allows for inter-person heterogeneity (i.e., unobserved differences between individuals) (Cameron and Trivedi 1986). The probability of at least one visit to a GP and the frequency of GP visits were estimated as a function of CSC, ISC, demographic characteristics (e.g., age and sex), socio-economic status (e.g., household income and education) and health status (e.g., self-reported health and number of chronic conditions). These equations were estimated on separate immigrant and non-immigrant subsamples as well as on a pooled sample of immigrants and non-immigrants. In the pooled models, a dummy variable was included to indicate immigrant status along with interaction terms consisting of the social capital variables and a variable to indicate duration of residency in Canada (number of years since immigration to Canada for the immigrant subsample and age for the non-immigrant subsample). All analyses were conducted using Stata v. 10.1 IC. Approval was obtained from the University of Toronto's Research Ethics Board.

\section{Results}

Immigrants are older, self-report poorer health and made $30.6 \%$ more GP visits than non-immigrants (Table 1). On average, the immigrants in our sample had lived in Canada for 27.7 years, with a standard deviation of 15 years. Moreover, given that $95 \%$ of the immigrants had resided in Canada for 13 to 75 years, the sample is primarily composed of long-term immigrants. The stock of CSC in the areas where immigrants and non-immigrants reside is similar, as were the proportions of immigrants and non-immigrants who reported tangible support and affection. Differences in religious attendance and a sense of belonging to the local community were observed between immigrants and non-immigrants. Table 1 presents the sample characteristics. 
Deborah A. Samek et al.

TABLE 1. Descriptive results for immigrants, non-immigrants and the pooled sample

\begin{tabular}{|c|c|c|c|c|c|c|}
\hline Variable & $\begin{array}{c}\text { Immigrants } \\
\text { (mean/\%) } \\
n=1,858\end{array}$ & $\begin{array}{c}\text { Std. } \\
\text { Deviation }\end{array}$ & $\begin{array}{c}\text { Non- } \\
\text { immigrants } \\
\text { (mean/\%) } \\
n=5,853\end{array}$ & $\begin{array}{c}\text { Std. } \\
\text { Deviation }\end{array}$ & $\begin{array}{c}\text { Full Sample } \\
\text { (mean/\%) } \\
n=7,711\end{array}$ & $\begin{array}{c}\text { Std. } \\
\text { Deviation }\end{array}$ \\
\hline GP visit & 4.91 & 5.07 & 3.86 & 4.64 & 4.21 & 4.81 \\
\hline $\mathrm{PSCl}$ & 1.12 & 0.14 & 1.13 & 0.21 & 1.13 & 0.19 \\
\hline \multicolumn{7}{|l|}{ Belonging } \\
\hline Very strong & 25.12 & - & 15.62 & - & 15.73 & - \\
\hline Strong & 15.95 & - & 41.83 & - & 41.57 & - \\
\hline Weak & 41.03 & - & 28.86 & - & 28.29 & - \\
\hline Very weak & 15.87 & - & 13.68 & - & $|4.4|$ & - \\
\hline Religious & 34.11 & - & 21.00 & - & 25.35 & - \\
\hline Tangible & 13.33 & 3.46 & 13.62 & 3.24 & 13.52 & 3.32 \\
\hline Affection & 10.39 & 2.39 & 10.82 & 2.11 & 10.68 & 2.22 \\
\hline Age* & 54.81 & 17.19 & 45.04 & 17.51 & 50.96 & 17.62 \\
\hline Female & 50.29 & - & 50.92 & - & 50.71 & - \\
\hline YSM* & 31.71 & 15.22 & - & - & - & - \\
\hline \multicolumn{7}{|l|}{ Continent of origin } \\
\hline North America & 3.38 & - & - & - & - & - \\
\hline South America & $|4.7|$ & - & - & - & - & - \\
\hline Asia & 33.55 & - & - & - & - & - \\
\hline Africa & 4.63 & - & - & - & - & - \\
\hline Europe & 40.40 & - & - & - & - & - \\
\hline Married & 67.41 & - & 59.12 & - & 61.87 & - \\
\hline Alone & 7.98 & - & 11.00 & - & 10.00 & - \\
\hline Household size & 3.64 & 1.64 & 3.09 & 1.43 & 3.24 & 1.51 \\
\hline College & 57.84 & - & 57.81 & - & 57.82 & - \\
\hline Income & 65,676 & 49,513 & 75,136 & 59,276 & 71,946 & 56,532 \\
\hline Employed full-time & 61.03 & - & 60.58 & - & 60.73 & - \\
\hline Alcohol & 5.46 & - & 8.72 & - & 7.64 & - \\
\hline \multicolumn{7}{|l|}{ SAH } \\
\hline Very poor & 12.26 & - & 9.62 & - & 10.48 & - \\
\hline Poor & 29.22 & - & 25.61 & - & 26.31 & - \\
\hline Good & 35.77 & - & 40.25 & - & 38.77 & - \\
\hline
\end{tabular}


TABLE 1. Continued

\begin{tabular}{|l|c|c|c|c|c|c|}
\hline \multicolumn{1}{|c|}{ Very good } & 22.75 & - & 24.52 & - & 23.94 & - \\
\hline Chronic condition & 65.48 & - & 70.58 & - & 68.89 & - \\
\hline CA & 2.12 & - & 9.17 & - & 6.83 & - \\
\hline
\end{tabular}

* These values include the extra four years resulting from the lagged analyses (i.e., utilization data collected four years after the socio-demographic variables). For example, the mean number of years since immigration to Canada in 2002 was 27.71 .

The first stage of the two-part model revealed that tangible social support tended to increase the propensity of immigrants (inter-rater reliability $[\mathrm{IRR}]=.047 ; p=.085$ ) to consult with a physician (Table $2^{4}$ ). Tangible social support was significantly associated with an increase in the likelihood that non-immigrants ( $\operatorname{IRR}=.038 ; p=.046$ ) would visit a GP. Although none of the social capital variables were significant in the immigrant intensity analysis, reporting affection tended to decrease the number of physician visits for non-immigrants (IRR=-.036; $p=.09)$. The pooled regression did not show a main effect for any of the social capital variables. The PSCI was not significant in the propensity (first-stage) or intensity (second-stage) analysis of any of the two-part models with the Heckman correction.

TABLE 2. Propensity and intensity of GP visits for immigrants

\begin{tabular}{|c|c|c|c|c|c|c|}
\hline \multirow[b]{2}{*}{ Variable } & \multicolumn{3}{|c|}{ Ist Stage } & \multicolumn{3}{|c|}{ 2nd Stage } \\
\hline & Coefficient & Std. Error & $p$-Value & Coefficient & Std. Error & $p$-Value \\
\hline Constant & -1.063 & 0.723 & .141 & 1.857 & 0.519 & .000 \\
\hline $\mathrm{PSCl}$ & 0.133 & 0.484 & .783 & -0.306 & 0.355 & .389 \\
\hline PSCI*YSM & -0.005 & 0.011 & .665 & 0.011 & 0.008 & .150 \\
\hline Belonging & -0.230 & 0.198 & .244 & -0.109 & 0.144 & .449 \\
\hline Belonging*YSM & 0.005 & 0.005 & .339 & 0.003 & 0.003 & .331 \\
\hline Religious & -0.124 & 0.153 & .417 & 0.050 & 0.103 & .627 \\
\hline Religious*YSM & 0.004 & 0.004 & .300 & -0.002 & 0.003 & .357 \\
\hline Tangible & 0.047 & 0.027 & $.085^{*}$ & -0.022 & 0.020 & .284 \\
\hline Tangible*YSM & -0.001 & 0.001 & .171 & 0.001 & 0.001 & .282 \\
\hline Affection & -0.049 & 0.041 & .227 & 0.027 & 0.030 & .366 \\
\hline Affection*YSM & 0.001 & 0.001 & .274 & -0.001 & 0.001 & .507 \\
\hline Phys Act & -0.089 & 0.078 & .250 & -0.049 & 0.052 & .337 \\
\hline Age & 0.055 & 0.013 & $.000 * *$ & 0.000 & 0.009 & .970 \\
\hline $\mathrm{Age}^{2}$ & 0.000 & 0.000 & $.000 * *$ & 0.000 & 0.000 & .166 \\
\hline Female & 0.332 & 0.072 & $.000 * *$ & 0.015 & 0.048 & .759 \\
\hline South America & 0.108 & 0.165 & .512 & 0.124 & 0.102 & .223 \\
\hline
\end{tabular}


Deborah A. Samek et al.

\begin{tabular}{|l|l|l|l|l|l|l|}
\hline Asia & 0.030 & 0.150 & .842 & 0.163 & 0.094 & $.083 *$ \\
\hline Africa & 0.091 & 0.220 & .679 & 0.106 & 0.136 & .436 \\
\hline Europe & -0.031 & 0.140 & .824 & -0.017 & 0.086 & .845 \\
\hline YSM & -0.001 & 0.015 & .943 & -0.014 & 0.011 & .204 \\
\hline Married & 0.167 & 0.102 & $.100 *$ & -0.048 & 0.068 & .481 \\
\hline Alone & -0.038 & 0.112 & .734 & -0.002 & 0.076 & .982 \\
\hline College & -0.134 & 0.074 & $.069 *$ & 0.008 & 0.046 & .868 \\
\hline Income & -0.007 & 0.016 & .662 & -0.009 & 0.011 & .376 \\
\hline Income & 0.001 & 0.001 & .358 & 0.000 & 0.000 & .563 \\
\hline Full-time & -0.204 & 0.105 & $.052 *$ & 0.113 & 0.067 & $.094 *$ \\
\hline Alcohol & 0.260 & 0.152 & $.088 *$ & -0.111 & 0.101 & .273 \\
\hline HDI Poor & 0.088 & 0.111 & .427 & -0.256 & 0.070 & $.000 * *$ \\
\hline HDI Good & 0.306 & 0.113 & $.007 * * 13$ & -0.385 & 0.070 & $.000 * *$ \\
\hline HDI Very good & 0.135 & 0.129 & .295 & -0.395 & 0.083 & $.000 * *$ \\
\hline Chronic & 0.435 & 0.086 & $.000 * * 12$ & 0.121 & 0.058 & $.038 *$ \\
\hline CA & -0.081 & 0.177 & .648 & -0.066 & 0.111 & .551 \\
\hline
\end{tabular}

* Significant at the $10 \%$ level

*** Significant at the $5 \%$ level

With respect to the negative binomial regression on the immigrant sample (Table 3), reporting a very strong or strong sense of belonging to the community tended to decrease the number of GP visits (IRR=.77; $p=.085)$. An interaction was observed between belonging to the community and the number of years since immigration ( $\operatorname{IRR}=.007 ; p=.070$ ), indicating that community belonging was associated with a smaller decrease in the number of doctor visits made by immigrants who had lived in Canada for a longer period of time.

For non-immigrants (Table 4), having tangible social support increased physician services utilization by a factor of $1.03(p=.035)$. The interaction between tangible social support and age was not significant. Affection (IRR=.95; $p=.037$ ) was associated with a decrease in physician visits, and a positive interaction term ( $I R R=.001 ; p=.035)$ suggested that affection decreased utilization for younger individuals and increased utilization for older individuals.

The PSCI was not significant in any of the NEGBIN regressions, nor were the social capital variables significant in the pooled NEGBIN regression (results not shown).

Other analyses (i.e., two-part model with the Heckman correction and NEGBIN) were conducted to examine the sensitivity of the model to the different SC variables, as well as to control for other types of primary care. Alternatives to GP visits were obtained from the CCHS, which asks respondents the number of times they consulted one of the following in the past 12 months for emotional problems, mental health or use of alcohol or drugs: psychia- 
TABLE 3. Intensity of GP visits for immigrants

\begin{tabular}{|c|c|c|c|}
\hline Variable & Coefficient & Std. Error & $p$-Value \\
\hline Constant & 0.360 & 0.550 & .513 \\
\hline $\mathrm{PSCl}$ & -0.186 & 0.375 & .620 \\
\hline PSCI*YSM & 0.008 & 0.009 & .383 \\
\hline Belonging & -0.263 & 0.153 & $.085 *$ \\
\hline Belonging*YSM & 0.007 & 0.004 & $.070 *$ \\
\hline Religious & -0.022 & 0.113 & .847 \\
\hline Religious*YSM & 0.000 & 0.003 & .941 \\
\hline Tangible & 0.014 & 0.020 & .484 \\
\hline Tangible*YSM & 0.000 & 0.001 & .817 \\
\hline Affection & -0.021 & 0.030 & .486 \\
\hline Affection*YSM & 0.001 & 0.001 & .458 \\
\hline Phys Act & -0.108 & 0.057 & $.058^{*}$ \\
\hline Age & 0.038 & 0.009 & $.000 * *$ \\
\hline $\mathrm{Age}^{2}$ & 0.000 & 0.000 & $.004 * *$ \\
\hline Female & 0.207 & 0.053 & $.000 * *$ \\
\hline South America & 0.210 & 0.119 & $.077 *$ \\
\hline Asia & 0.195 & 0.109 & $.072 *$ \\
\hline Africa & 0.185 & 0.161 & .251 \\
\hline Europe & 0.013 & 0.101 & .897 \\
\hline YSM & -0.017 & 0.012 & .159 \\
\hline Married & 0.067 & 0.072 & .356 \\
\hline Alone & -0.003 & 0.082 & .969 \\
\hline College & -0.073 & 0.053 & .165 \\
\hline Income & -0.014 & 0.012 & .221 \\
\hline Income ${ }^{2}$ & 0.001 & 0.000 & .156 \\
\hline Full-time & -0.006 & 0.075 & .934 \\
\hline Alcohol & 0.084 & 0.107 & .436 \\
\hline SAH Poor & -0.207 & 0.079 & $.009 * *$ \\
\hline SAH Good & -0.198 & 0.080 & $.013^{* * *}$ \\
\hline SAH Very good & -0.323 & 0.093 & $.001 * * *$ \\
\hline Chronic & 0.423 & 0.065 & $.000 * *$ \\
\hline CA & -0.090 & 0.129 & .486 \\
\hline
\end{tabular}

* Significant at the 10\% level

** Significant at the $5 \%$ level
TABLE 4. Intensity of GP visits for non-immigrants

\begin{tabular}{|c|c|c|c|}
\hline Variable & Coefficient & Std. Error & $p$-Value \\
\hline Constant & 0.794 & 0.331 & .017 \\
\hline $\mathrm{PSCl}$ & -0.282 & 0.189 & .136 \\
\hline PSCI*Age & 0.006 & 0.003 & $.084 *$ \\
\hline Belonging & 0.118 & 0.116 & .308 \\
\hline Belonging*Age & -0.002 & 0.002 & .450 \\
\hline Religious & -0.096 & 0.106 & .363 \\
\hline Religious*Age & 0.001 & 0.002 & .433 \\
\hline Tangible & 0.033 & 0.016 & $.035 * *$ \\
\hline Tangible*Age & 0.000 & 0.000 & .111 \\
\hline Affection & -0.052 & 0.025 & $.037 * *$ \\
\hline Affection*Age & 0.001 & 0.000 & $.035 * *$ \\
\hline Phys Act & -0.035 & 0.031 & .265 \\
\hline Age & 0.016 & 0.008 & $.043 * *$ \\
\hline $\mathrm{Age}^{2}$ & 0.000 & 0.000 & $.001 * *$ \\
\hline Female & 0.398 & 0.031 & $.000 * *$ \\
\hline Married & -0.018 & 0.044 & .678 \\
\hline Alone & -0.056 & 0.049 & .258 \\
\hline College & -0.034 & 0.031 & .263 \\
\hline Income & -0.006 & 0.006 & .288 \\
\hline Income ${ }^{2}$ & 0.000 & 0.000 & .295 \\
\hline Full-time & -0.070 & 0.039 & $.076 *$ \\
\hline Alcohol & -0.026 & 0.050 & .601 \\
\hline SAH Poor & -0.166 & 0.050 & $.001 * * *$ \\
\hline SAH Good & -0.238 & 0.049 & $.000 * *$ \\
\hline SAH Very good & -0.297 & 0.055 & $.000 * *$ \\
\hline Chronic & 0.324 & 0.036 & $.000 * *$ \\
\hline CA & -0.144 & 0.044 & $.001 * *$ \\
\hline
\end{tabular}

* Significant at the $10 \%$ level;

** Significant at the $5 \%$ level 
trist, family doctor, psychologist, social worker and religious adviser. Given that merging the CCHS with the Census resulted in sample attrition, regressions were run separately on the unmerged immigrant $(n=2,091)$ and non-immigrant $(n=8,073)$ samples without including the PSCI and CA. Results for the two-part model show that for immigrants none of the ISC indicators, when entered separately or all together in the model, were significant. When the ISC variables were entered separately, however, self-reported visits to a family doctor in 2002 increased the propensity to visit a GP in 2006-2007 (e.g., IRR=.167; $p=.001$ ), and consulting with a psychologist increased the number of future visits made to a GP (e.g., IRR=.163; $p=.015)$. The regression results for the non-immigrant sample were more diverse. For example, when all the ISC variables were entered into the model, attending at least one religious service increased the propensity to make a GP visit and decreased the number of GP visits (propensity: IRR $=.134 ; p=.001$; frequency: IRR $=-.068 ; p=.007)$. When entered separately, religious attendance $(\operatorname{IRR}=.144 ; p=.001)$, affection $(\operatorname{IRR}=.022 ; p=.002)$ and tangible social support $(\mathrm{IRR}=.016 ; p=.001)$ increased the propensity to consult with a GP. It should be noted that reporting consultations with a family doctor increased the intensity of GP consultations four years into the future in all models.

With respect to the one-stage NEGBIN, when all the ISC variables were entered, reporting a strong sense of belonging decreased the number of GP visits for immigrants $(\mathrm{IRR}=-.289 ; p=.038)$. This finding was strengthened when belonging was entered separately in the model (IRR=-.301; $p=.029$ ). None of the alternative sources of medical care were significant in any of the immigrant NEGBIN regressions. The findings from the non-immigrant NEGBIN showed that none of the ISC variables were significant, although consulting a family doctor increased the frequency of future GP visits for all models.

Regressions that included only CSC and other covariates were based on the immigrant and non-immigrant subsamples, with missing data because two data sources are required to create the PSCI. For immigrants, the two-part model showed an interaction between the PSCI and the number of years since immigration in the intensity analysis (IRR $=.016$; $p=.039)$. Although the PSCI was not significant in the non-immigrant two-part model, living alone significantly decreased the propensity to visit the GP (IRR $=-.310 ; p=.000)$ and increased the number of visits (IRR $=.091 ; p=.028$ ). The PSCI was not significant in the immigrant and non-immigrant NEGBIN regressions, respectively. We also re-ran the regressions from the main analysis using the PSCI derived from the 2005 Census (i.e., the future stock of CSC); the findings were unchanged.

Health status was the strongest driver of physician consultations. In the two-part regressions, having at least one chronic condition and self-reporting poorer health significantly increased the propensity to visit the GP and the intensity of GP visits for both immigrants and non-immigrants. Similar results were observed in the NEGBIN models. Age and sex (i.e., female) were consistently significant in the immigrant and non-immigrant models and were both associated with an increased propensity to consult with a GP and, in the NEGBIN models, an increased frequency of visits. For non-immigrants, residing in a CA (IRR=-.144; 
$p=.001)$ and being employed full-time (IRR $=-.07 ; p=.076)$ decreased the number of annual GP visits. The Heckman regression on immigrants showed that having at least a college degree (IRR $=-.134 ; p=.069)$ and being employed full-time (IRR=-.204; $p=.052)$ decreased the propensity to consult with a physician. Finally, participation in physical activity was associated with a decreased number of doctor visits (IRR $=-.108 ; p=.058)$ in the NEGBIN immigrant model.

\section{Discussion}

Unexpectedly, our measure of CSC was not significant in any of the analyses. The descriptive results indicate an average value of the PSCI of $1.12 \%$ and $1.13 \%$ for communities in which immigrants and non-immigrants live, respectively. These numbers suggest that there is little difference in the CSC resources available to immigrants and non-immigrants within CAs and CMAs, which may explain the weak performance of the PSCI. An alternative explanation is that the PSCI is not sensitive to CSC that is found outside of an employee-employer relationship. Moreover, this indicator excludes regions smaller than a CA; therefore, community effects that may operate at the level of the neighbourhood may not be detected. The PSCI provides a proxy for the level of community resources; it does not, however, reveal how much of those resources are accessible to any particular individual.

It was expected that ISC would encourage immigrants to consult more often with the doctor, and it is surprising that opposite results were found. The results suggest that for immigrants some aspect of community belonging (e.g., norms of behaviour, network size and density, or degree of integration) may substitute for formal health services utilization (Deri 2004; Laporte et al. 2008; Shields 2008). Community belonging may be conceptualized as a measure of integration into the community (e.g., immigrant or ethnic community or the host society). Thus, the degree of community belonging may reflect use of community resources (e.g., religious or cultural groups) that substitute for formal healthcare and for the care normally given by relatives (Aroian et al. 2001).

In general, recent immigrants who have not yet developed extensive social networks are more reliant on resources from family and friends; long-term immigrants are more likely to depend on community services (Stewart et al. 2008). Thus, given that our sample was composed primarily of long-term immigrants, the variable "sense of belonging to the local community" may in fact be an indicator of CSC. This hypothesis is strengthened by findings from the sensitivity analysis suggesting that CSC is associated with a greater decrease in doctor visits for immigrants who have lived in Canada for a longer period of time.

The results suggest a complex role for ISC in influencing health services utilization of non-immigrants. Experiencing and giving affection may substitute for formal healthcare services, whereas tangible social support may be complementary to formal healthcare use. Social support, which is often provided by family and friends (Leclere et al. 1994), seems to serve as a substitute for formal care in this case. Having a network of family and friends can assist formal healthcare services use by providing transportation to the clinic, transmitting information 
about the healthcare system and lending money to purchase prescription drugs (Deri 2004; Viladrich 2005; Devillanova 2008; Laporte et al. 2008; Nakhaie et al. 2007). Future research efforts should perhaps make use of qualitative assessment techniques to characterize the precise nature of the various aspects of ISC that affect health services use.

There are important limitations to the merged CCHS and OHIP data set. For example, very recent immigrants (i.e., less than five years in Canada) are excluded from the sample (there is a five-year lag between the collection of the socio-demographic information and the utilization data). This lack of more recent immigrants may be responsible for the non-significant findings in the pooled analysis. Given that the immigrants in this sample have resided in Canada for many years, they may not use GP visits differently than non-immigrants.

Furthermore, the exclusion of certain types of healthcare (e.g., hospitalization, community health centre [CHC] visits, GPs who work non-fee-for-service, and alternative or traditional medicine) from the OHIP administrative data may lead to spillover effects in these unmeasured areas of healthcare use. Utilization statistics of these various services were unavailable; we were thus limited to examining frequency of the utilization of GP services.

\section{Conclusion}

The findings provide new evidence that the use of primary care services by immigrants may be influenced by their degree of belonging to the local community and support the existing literature in documenting the enabling and substitution effects of ISC. This analysis attempts to highlight the importance of recognizing that the healthcare system has both formal and informal components and that policy makers should be aware of the potential for interactive effects between the two. Moreover, social capital may be a key factor in eliminating the barriers immigrants face to accessing the healthcare system or providing alternatives to formal healthcare.

Investment in community resources may be beneficial to various immigrant communities, as previous research has determined that the community is an important provider of healthcare to immigrants and that segments of this population have a noted preference for traditional medicine. Shifting investment from the formal healthcare system to community organizations that may substitute for formal healthcare may not be the best solution. Conducting primary data collection on recent immigrants may help researchers determine ways to develop supports for this group in order to prevent the negative outcomes seen in their long-term counterparts.

\section{ACKNOWLEDGEMENTS}

Financial support was provided through Dr. Audrey Laporte's CIHR grant \#153093 and a SSHRC Canadian Graduate Master's Award. Access to the data was provided by the Ontario Ministry of Health and Long-Term Care; however, the opinions expressed do not represent the views of the Ministry.

The primary author would like to thank all her reviewers for their helpful comments on an earlier draft of this paper and on her thesis, especially the external examiner, Dr. Bruce Newbold. 
Correspondence may be directed to: Dr. Audrey Laporte, Institute of Health Policy, Management and Evaluation, Faculty of Medicine, University of Toronto, Health Sciences Building, 4th Floor, 155 College Street, Suite 425, Toronto, ON M5T 3MS; tel.: 416-946-7386; e-mail: audrey. laporte@utoronto.ca.

\section{NOTES}

${ }^{1}$ The data set employed in this paper differs from the one in Laporte and colleagues' (2008) study in the following ways: sample is composed only of respondents from Ontario, the subsequent wave of the Canadian Community Health Survey is used, and the outcome variable is derived from physician claims from the Ontario Health Insurance Program rather than wave 1.1 of the CCHS.

${ }^{2}$ This variant of the PSCI differs from the original PSCI constructed by Scheffler and Brown (2008), who used the total population as the denominator. Using the number of paid employees over the age of 15 avoids bias from varying economic conditions across the country. In our formulation, local economic conditions will have a similar impact on the numerator and denominator of the proportion, whereas in the original formulation, only the numerator is affected (Laporte et al. 2008).

${ }^{3}$ The average number of years since immigration includes the four years added for the utilization data. That is, the demographic information dates from 2002, but the utilization data are from 2006; therefore, four years were added to the variable for number of years since immigration, as well as to the age variable.

${ }^{4}$ Results are shown only for the immigrant sample because this is the population of interest in this analysis.

\section{REFERENCES}

Ahern, M.M. and M.S. Hendryx. 2005. "Social Capital and Risk for Chronic Illness." Chronic Illness 1: 183-90.

Aroian, K.J., G. Khatutsky, T.V. Tran and A.L. Balsam. 2001.“Health and Social Service Utilization among Elderly Immigrants from the former Soviet Union." Journal of Nursing Scholarship 33(3): 265-71.

Asanin, J. and K. Wilson. 2008. “I Spent Nine Years Looking for a Doctor': Exploring Access to Health Care among Immigrants in Mississauga, Ontario, Canada." Social Science and Medicine 66: 1271-83.

Bhattacharya, G. 2005. "Social Capital and HIV Risks among Acculturating Asian Indian Men in New York City." AIDS Education and Prevention 17(6): 555-67.

Brown, T.T., R.M. Scheffler, S. Seo and M. Reed. 2006."The Empirical Relationship between Community Social Capital and the Demand for Cigarettes." Health Economics 15: 1159-72.

Bryant, C.-A. and D. Norris. 2002. “Measurement of Social Capital: The Canadian Experience." OECD Country Report for International Conference on Social Capital Measurement, London, England.

Cameron, A.C. and P.K. Trivedi. 1986."Econometric Models Based on Count Data: Comparisons and Applications of Some Estimators and Tests." Journal of Applied Econometrics 1(1): 29-53.

Deri, C. 2004. “Understanding the 'Healthy Immigrant Effect' in Canada." No. 0502E, Working Papers, University of Ottawa, Department of Economics. Retrieved June 7, 2012. <http://econpapers.repec.org/ RePEc:ott:wpaper:0502e>.

Deri, C. 2005. “Social Networks and Health Service Utilization." Journal of Health Economics 24: 1076-107.

Devillanova, C. 2008. “Social Networks, Information and Health Care Utilization: Evidence from Undocumented Immigrants in Milan." Journal of Health Economics 27: 265-86.

Dunlop, S., P.C. Coyte and W. McIsaac. 2000. “Socio-Economic Status and the Utilisation of Physicians' Services: Results from the Canadian National Population Health Survey." Social Science and Medicine 51(1): 123-33.

Folland, S. 2008. "An Economic Model of Social Capital and Health." Health Economics, Policy and Law 3: 333-48. Gerdtham, U.-G. 1997. “Equity in Health Care Utilization: Further Tests Based on Hurdle Models and Swedish Micro Data." Econometrics and Health Economics 6: 303-19. 
Glaeser, E.L., D. Laibson and B. Sacerdote. 2002. “An Economic Approach to Social Capital.” Economic Journal 112: F437-58.

Greene, W. 2003. Econometric Analysis (5th ed.). Upper Saddle River, NJ: Prentice Hall.

Heckman, J.J. 1976. “Sample Selection Bias as a Specification Error.” Econometrica 47(1): 153-61.

Hendryx, M.S., M.M. Ahern, N.P. Lovrich and A.H. McCurdy. 2002. "Access to Health Care and Community Social Capital." Health Services Research 37(1): 85-101.

Hyman, I. 2001. "Immigration and Health." Health Policy Working Paper Series (Working Paper No. 01-05). Ottawa: Health Canada. Retrieved June 7, 2012. <http://www.ceris.metropolis.net/wp-content/uploads/pdf/ research_publication/working_papers/wp55.pdf >.

Kao, G. 2004. “Social Capital and Its Relevance to Minority and Immigrant Populations." Sociology of Education 77: 172-83.

Kunz, J. 2005. "Orienting Newcomers to Canadian Society: Social Capital and Settlement." In Social Capital in Action: Thematic Policy Studies (pp. 52-64). Ottawa: Policy Research Initiative.

Laporte, A., E. Nauenberg and L. Shen. 2008. "Aging, Social Capital and Health Care Utilization in Canada." Health Economics, Policy and Law 3: 393-411.

Laroche, M. 2000. “Health Status and Health Services Utilization of Canada's Immigrant and Non-Immigrant Populations." Canadian Public Policy 26(1): 51-75.

Leclere, F.B., L. Jensen and A.E. Biddlecom. 1994."Health Care Utilization, Family Context, and Adaptation among Immigrants to the United States." Journal of Health and Social Behavior 35: 370-84.

Leduc, N. and M. Proulx. 2004. “Patterns of Health Services Utilization by Recent Immigrants." Journal of Immigrant Health 6(1): 15-27.

Ma, G.X. 1999.“Between Two Worlds: The Use of Traditional and Western Health Services by Chinese Immigrants." Journal of Community Health 24(6): 421-37.

Macinko, J. and B. Starfield. 2001. "The Utility of Social Capital in Research on Health Determinants." Milbank Quarterly 79(3): 387-427.

McMichael, C. and L. Manderson. 2004."Somali Women and Well-Being: Social Networks and Social Capital among Immigrant Women in Australia." Human Organization 63(1): 88-99.

Mellor, J.M. and J. Milyo. 2005. "State Social Capital and Individual Health Status." Journal of Health Politics, Policy and Law 30(6): 1101-30.

Miltiades, H.B. and B. Wu. 2007."Factors Affecting Physician Visits in Chinese and Chinese Immigrant Samples." Social Science and Medicine 66: 704-14.

Nabalamba, A. and W.J. Millar. 2007. "Going to the Doctor." Health Reports 18(1): 23-35. Ottawa: Statistics Canada.

Nakhaie, M.R., L.K. Smylie and R. Arnold. 2007. “Social Inequalities, Social Capital and Health of Canadians.” Review of Radical Political Economics 39(4): 562-85.

Pavlic, D.R., B. Brovc, I. Svab, J. Ahcin and M. Slajpah. 2007. “Attitudes to Illness and Use of Health Services by Economic Immigrants in Slovenia." Croatian Medical Journal 48: 675-83.

Pohlmeier, W. and V. Ulrich. 1995. "An Econometric Model of the Two-Part Decision-Making Process in the Demand for Health Care." Journal of Human Resources 30(2): 339-61.

Puhani, P.A. 2000."The Heckman Correction for Sample Selection and Its Critique." Journal of Economic Surveys 14(1): 53-68.

Putnam, R.D. 2000. Bowling Alone: The Collapse and Revival of American Community. New York: Simon \& Schuster.

Scheffler, R.M. and T.T. Brown. 2008. "Social Capital, Economics and Health: New Evidence." Health Economics, Policy and Law 3: 321-31.

Shields, M. 2008. “Community Belonging and Self-Perceived Health." Health Reports 19(2): 1-10. Statistics Canada Catalogue no. 82-003-XWE. Retrieved June 7, 2012. <http://www.statcan.gc.ca/cgi-bin/af-fdr. 
cgi?l=eng\&loc=http://www.statcan.gc.ca/pub/82-003-x/2008002/article/10552-eng.pdf\&t $=$ Community\%20 belonging\%20and\%20 self-perceived\%20health $>$.

Statistics Canada. n.d. 2002 Canadian Community Health Survey (CCHS) Cycle 1.2: Derived Variable (DV) Specifications. Retrieved June 7, 2012. <http://www23.statcan.gc.ca:81/imdb-bmdi/pub/document/5015_D8_ T9_V1-eng.pdf>.

Statistics Canada. 2004. Canadian Community Health Survey (CCHS) Cycle 1.2: Data Dictionary, Share file Ontario.

Stewart, M., J. Anderson, M. Beiser, E. Mwakarimba, A. Neufeld, L. Simich et al. 2008. "Multicultural Meanings of Social Support among Immigrants and Refugees." International Migration 46(3): 124-58.

Subramanian, S.V. and I. Kawachi. 2004. "Income Inequality and Health: What Have We Learned So Far?" Epidemiologic Reviews 26: 78-91.

Viladrich, A. 2005. "Tango Immigrants in New York City: The Value of Social Reciprocities." Journal of Contemporary Ethnography 34(5): 533-59.

Wu, Z. and R. Hart. 2002."Social and Health Factors Associated with Support among Elderly Immigrants in Canada." Research on Aging 24(2): 391-412.

\section{Appendix}

Characteristics of sample without missing data due to matching CA with the Census

\begin{tabular}{|c|c|c|c|c|}
\hline Variable & $\begin{array}{c}\text { Immigrants } \\
(\text { mean/\%) } \\
n=2,091\end{array}$ & Std. Deviation & $\begin{array}{c}\text { Non-Immigrants } \\
\begin{array}{c}(\text { mean } / \%) \\
n=8,073\end{array}\end{array}$ & Std. Deviation \\
\hline GP visit & 4.94 & 5.16 & 3.96 & 4.77 \\
\hline \multicolumn{5}{|l|}{ Belonging } \\
\hline Very strong & $|8.5|$ & & 18.25 & \\
\hline Strong & 40.27 & & 42.60 & \\
\hline Weak & 26.64 & & 26.94 & \\
\hline Very weak & 14.59 & & 12.21 & \\
\hline Religious & 33.05 & & 21.88 & \\
\hline Tangible & 13.04 & 3.77 & 13.32 & 3.58 \\
\hline Affection & 10.29 & 2.54 & 10.63 & 2.36 \\
\hline Age & 55.80 & 18.83 & 48.79 & 19.03 \\
\hline Female & 54.94 & & 53.54 & \\
\hline YSM & 33.61 & 17.92 & & \\
\hline \multicolumn{5}{|l|}{ Continent of origin } \\
\hline North America & 5.69 & & & \\
\hline South America & 12.29 & & & \\
\hline Asia & 21.43 & & & \\
\hline Africa & 3.87 & & & \\
\hline Europe & 54.66 & & & \\
\hline
\end{tabular}


Deborah A. Samek et al.

\begin{tabular}{|c|c|c|c|c|}
\hline Others & 2.06 & & & \\
\hline Married & 58.15 & & 52.07 & \\
\hline Alone & 24.39 & & 24.33 & \\
\hline Household size & 2.65 & 1.51 & 2.56 & 1.36 \\
\hline College & 57.29 & & 54.22 & \\
\hline Income & 36,152 & 50,646 & 41,510 & 53,781 \\
\hline Employed full-time & 49.54 & & 55.42 & \\
\hline Alcohol & 6.22 & & 9.39 & \\
\hline \multicolumn{5}{|l|}{ SAH } \\
\hline Very poor & 14.30 & & 12.38 & \\
\hline Poor & 29.60 & & 26.06 & \\
\hline Good & 35.15 & & 38.85 & \\
\hline Very good & 20.95 & & 22.71 & \\
\hline Chronic condition & 73.08 & & 74.90 & \\
\hline \multicolumn{5}{|l|}{ Visit for mental health } \\
\hline Psychiatrist & 0.42 & 8.29 & 0.37 & 2.66 \\
\hline Family doctor & 0.19 & 2.11 & 0.32 & 3.53 \\
\hline Psychologist & 0.00 & 0.08 & 0.06 & 3.72 \\
\hline Social worker & 0.26 & 8.03 & 0.48 & 7.57 \\
\hline Religious adviser & 0.11 & 1.92 & 0.22 & 5.30 \\
\hline
\end{tabular}

